\title{
Visceral adipose tissue in children and adolescents: a review
}

\author{
Edyta Suliga \\ Institute of Public Health, Jan Kochanowski University, Aleja IX Wieków Kielc 19, 25-317 Kielce, Poland
}

Research conducted among adults has mainly shown that visceral adipose tissue (VAT) is strongly linked to insulin resistance, type 2 diabetes, hypertension and dyslipidaemia, leading to increased risk of CVD or the metabolic syndrome. However, little is known about the aetiology, determinants and consequences of VAT in children. The present article reviews the current literature relating to the factors influencing visceral fat accumulation in children and adolescents. The literature used in the present study was collected by searching a PubMed database, in which studies up to 2008 exploring the factors influencing accumulation of visceral fat among children and youth were found on the basis of appropriate keywords. Further studies concerning different factors influencing deposition of VAT among children and youth should first of all concentrate on: carrying out long-term analyses among children of different ethnical groups, which should begin in the period of prepuberty and which should cover the whole period of puberty till adulthood; drawing up norms specifying the amount of VAT among healthy children; identification of anthropometric indicators which will help to determine the VAT:subcutaneous adipose tissue ratio in the most precise way; broader studies of the influence of eating habits on developing VAT deposit among children and youth.

Visceral adipose tissue: Determinants of visceral fat accumulation: Children: Adolescents

\section{Introduction}

Abdominal obesity is determined by the accumulation of both subcutaneous adipose tissue (SAT) and visceral adipose tissue (VAT). VAT depots, located in the body cavity beneath the abdominal muscles, are composed of the greater and lesser omentum (peritoneum that is attached to the stomach and links it with other abdominal organs) and mesenteric fat ${ }^{(1)}$. Most investigators report VAT as intra-abdominal adipose tissue (IAAT) ${ }^{(2)}$. According to the five-level body composition model 'adipose tissue' and 'fat' are different components ${ }^{(3)}$. Adipose tissue is the tissuesystem level component, and includes components such as adipocytes at the cellular level and lipids at the molecular level ${ }^{(4)}$. Adipose tissue contains $80 \%$ fat. The remaining $20 \%$ is water, protein and minerals ${ }^{(5)}$. The distinction between fat and adipose tissue in common usage is usually irrelevant, and the terms are almost always used interchangeably ${ }^{(2)}$. VAT is known to exhibit morphological and functional differences in comparison with SAT. Research conducted among adults has mainly shown that it is strongly linked to insulin resistance, type 2 diabetes, hypertension and dyslipidaemia, leading to increased risk of CVD or the metabolic syndrome ${ }^{(1,6-8)}$. However, little is known about the aetiology, determinants and consequences of VAT in children. The present article reviews the current literature relating to the factors influencing visceral fat accumulation in children and adolescents.

Literature used in the present study was collected by searching a PubMed database up to 2008 using the following keywords: 'abdominal', 'intraabdominal', or 'visceral' and 'fat' or 'adipose tissue'; 'fatness distribution'; 'determinants of abdominal obesity'; 'children' or 'adolescents'. At the initial phase, there were selected mainly the studies in which direct measurement methods of VAT were applied. Several studies were selected from reference lists cited in the selected studies. As the influence of many factors determining the amount of VAT depot among children and youth was not widely analysed in the studies using direct methods of VAT measurement, the literature has been supplemented with some studies using indirect measurements as well as results of some studies carried out among adults.

Abbreviations: CT, computed tomography; DXA, dual-energy X-ray absorptiometry; GH, growth hormone; HERITAGE, HEalth, RIsk factors, exercise Training And GEnetics; $11 \beta$-HSD1, $11 \beta$-hydroxysteroid dehydrogenase type 1; HPA, hypothalamic-pituitary-adrenal; IAAT, intra-abdominal adipose tissue; SAT, subcutaneous adipose tissue; VAT, visceral adipose tissue.

Corresponding author: Dr Edyta Suliga, fax + 48 413496948, email Edyta.Suliga@pu.kielce.pl 


\section{The measuring of visceral adipose tissue quantity}

Computed tomography (CT) and MRI provide the most precise estimates of internal adipose tissue deposition in children ${ }^{(9)}$. VAT is usually characterised by measuring the VAT area at the $\mathrm{L}_{4}-\mathrm{L}_{5}$ vertebral interspace ${ }^{(10)}$. Siegel et al. ${ }^{(11)}$ described recently a quick and reproducible singlesection magnetic resonance method for quantifying subcutaneous and visceral abdominal fat and its distribution in preadolescents and adolescents. MRI does not require exposure to ionising radiation, making it advantageous over CT, particularly for multiple measurements. However, MRI is also expensive and not widely available for research. An alternative method of assessing visceral adiposity may be ultrasonography ${ }^{(12,13)}$.

Indirect measurements of visceral fat include dual-energy X-ray absorptiometry (DXA) to measure fat mass in the trunk region and anthropometry. The main limitation of DXA assessment of body composition is the inability to distinguish subcutaneous from intra-abdominal fat mass ${ }^{(14)}$. Bouchard $^{(15)}$, analysing the results from the HEalth, RIsk factors, exercise Training And GEnetics (HERITAGE) Family Study and the Quebec Family Study, stated that BMI $(r 0.72)$, fat mass $(r 0.73)$ and waist circumference $(r 0.77)$ are equally well correlated with CT-assessed abdominal visceral fat. Moreover, waist circumference is very strongly correlated with BMI $(r$ 0.93) and fat mass $(r$ 0.92). These results show that each of these indicators can be useful as an indirect measure of VAT.

Goran et al. ${ }^{(16)}$, investigating the relationship of IAAT and SAT with body composition and anthropometry in prepubertal children, showed that intra-abdominal fat was most strongly correlated with abdominal skinfold ( $r$ 0.88) and trunk fat measured by DXA ( $r$ 0.87). In stepwise regression intra-abdominal fat was best predicted by trunk fat from DXA, total fat from DXA and abdominal skinfold $\left(R^{2} 0 \cdot 85\right)$. Benfield et al. ${ }^{(17)}$, analysing validity of DXA for the estimation of MRI-assessed abdominal adiposity in 13-year-old children, found that DXA-derived trunk fat explained 78.1 and $67.3 \%$ of the variance of IAAT in boys and girls, respectively. However, DXA total body fat predicted SAT to a slightly higher degree than VAT $(92.2 \%$ of SAT variance in boys and $79.9 \%$ in girls). The authors concluded that DXA regional trunk fat mass is a relatively good proxy measure of IAAT at the group level but not at the individual level. In the absence of DXA data, intra-abdominal fat was best predicted by abdominal skinfold, ethnicity and subscapular skinfold $\left(R^{2} 0 \cdot 82\right)^{(16)}$. Fox et al. ${ }^{(18)}$, in long-term examination of children aged 11-13 years, stated that acceptable indicators of IAAT deposition were truncal skinfolds ( $r$ 0.54-0.70). Ball et al. ${ }^{(19)}$, investigating overweight 8- to 13-year-old Latino children, found that the strongest univariate correlate for VAT was waist circumference $(r 0 \cdot 65)$. Regression analyses showed that approximately $50 \%$ of the variance in VAT was explained by waist circumference $(43.8 \%)$, Tanner stage $(4.2 \%)$ and calf skinfold $(1.7 \%)$. The correlation between body fat percentage and visceral fat among healthy teenagers aged 14-18 years was exactly the same as Bouchard's ${ }^{(15)}$, which was $r 0.73^{(20)}$. Examination of Japanese obese boys showed that out of anthropological indices the sagittal diameter was the best surrogate of visceral fat measure, and a threshold value which helped to single out those with metabolism disorder was $19.2 \mathrm{~cm}^{(21)}$. Further studies carried out among obese girls and boys aged $6-15$ years showed that waist circumference of $82 \mathrm{~cm}$ can be a proper diagnostic criterion ${ }^{(22)}$.

Owens et al. ${ }^{(23)}$, examining obese teenagers, created an equation helping value the quantity of visceral fat from simple anthropometric measurements. The stepwise multiple regression procedure yielded a final model that included two anthropometric variables (sagittal diameter and waist:hip ratio) and one demographic variable (ethnicity). The prediction equation was: VAT $=-124.06+16 \cdot 67$ (ethnicity - coded as $0=$ black and $1=$ white) $+4 \cdot 15$ (sagittal diameter) $+100 \cdot 89$ (waist: hip ratio). The model explained $63 \%$ of the variance in VAT and was associated with a measurement error of $23.9 \%$. In the study of children and adolescents aged 7-16 years, univariate regression analysis identified waist circumference as the best single predictor of VAT (64.8\% of variance) and BMI of SAT $(88.9 \% \text { of variance })^{(24)}$. The authors created prediction equations for VAT $\left(\mathrm{cm}^{2}\right)=1.1 \times$ waist circumference $(\mathrm{cm})-52 \cdot 9$. The cross-validation of the VAT algorithm was acceptable, but a root mean square error of $33 \%$ for the estimate of VAT from waist circumference is relatively high both at the population and individual level. Benfield et al. (25) showed that waist circumference predicted $67.4 \%$ of the variance in VAT. BMI as the best single predictor explained only $8.4 \%$ of the variance in the VAT:SAT ratio.

Recent studies have shown that a specific marker for visceral fat accumulation in obese children can be plasma visfatin levels $^{(26)}$.

To sum up, it has to be stated that out of indirect VAT predictors among children and youth the most useful ones seem to be: trunk fat measured by DXA, trunk skinfolds as well as waist circumference and sagittal diameter. However, their usefulness has to be confirmed in long-term studies, as their mutual relationships can change with age according to $\operatorname{sex}^{(24)}$.

\section{Visceral fat and metabolic risk factors}

One of the first studies of the relationship between abdominal visceral fat and metabolic risk factors in adolescents was carried out by Caprio et al. ${ }^{(27)}$. In obese adolescent girls a positive correlation was found between fasting TAG levels and visceral fat, whereas an inverse relationship was noted between HDL-cholesterol and visceral fat depots. A significant relationship was found between the amount of visceral fat and both insulin secretion and sensitivity ${ }^{(28)}$. Specifically, visceral fat correlated with basal ( $r$ 0.89) and stimulated insulin responses $(r 0.61)$ and inversely correlated with the M/I index of insulin sensitivity $(r-0.63)$ (the ratio between glucose infusion rate and plasma insulin levels during the hyperglycaemic clamp) and insulin-stimulated glucose metabolism measured during the euglycaemic clamp study $(r-0.87)$. In contrast to the strong relationship between visceral fat mass and insulin secretion and sensitivity, no significant correlation was found in the obese group 
between subcutaneous fat, pelvic fat, and these metabolic measurements. Brambilla et al. ${ }^{(29)}$ showed that in postpubertal children the relationship of IAAT to clinically significant risk factors resembles the pattern in obese adults.

Anthropometric measures of abdominal adiposity of children and adolescents also showed that similarly to adults, children's fatty acid composition of abdominal adipose tissue is less favourable than that of the buttock depots $^{(30)}$. Abdominal depots had elevated proportions of SFA and reduced proportions of monounsaturated and polyunsaturated fat in comparison with buttock depots. Moreover, children's abdominal depots appear to have higher trans-fatty acid contents than buttock depots. Children's adipose polyunsaturated fat, a biomarker of long-term PUFA intake, was inversely related to serum total cholesterol and LDL-cholesterol. The results of investigations by Daniels et al. ${ }^{(31)}$ also showed that fat distribution is a more important independent correlate of cardiovascular risk factors than body fat percentage in children and adolescents (aged 9-17 years). Greater deposition of central fat (an android fat pattern) was associated with less favourable plasma lipid and lipoprotein concentrations, blood pressure and left ventricular mass. Significant positive relationships between systolic and diastolic blood pressure and trunk fat adjusted for total fat in boys was found by He et al. ${ }^{(32)}$

Kortelainen \& Särkioja ${ }^{(33)}$ found that early macrophagerich coronary lesions were associated with increased amounts of visceral fat in adolescent male individuals.

Later investigations based on direct measures of VAT confirmed that increased total cholesterol $(>1700 \mathrm{mg} / \mathrm{l})$ was associated with visceral fat, and also with a serum insulin $>17 \mu \mathrm{U} / \mathrm{ml}$ in those teenagers with Tanner I or II pubertal stages ${ }^{(34)}$. Among children being overweight or obese, VAT was significantly related to risk factors for the metabolic syndrome. However, such association was not observed in the case of SAT as well as total fat mass ${ }^{(35)}$. The metabolic syndrome was completely absent in adolescents with low VAT while it was present in $13.8 \%$ of males and $8.3 \%$ females with high $\operatorname{VAT}^{(36)}$

VAT was independently correlated with blood pressure, TAG, HDL-cholesterol, fasting insulin and the homeostasis model assessment of insulin resistance (HOMA) score, while SAT was independently correlated with systolic blood pressure, fasting insulin and the HOMA score among obese Korean adolescents ${ }^{(37)}$. Leucocyte count (an inflammatory marker) was positively related to abdominal obesity in female obese adolescents, but the relationship was more distinguishable with subcutaneous than visceral $\operatorname{adiposity}^{(38)}$. The study of Polat et al. ${ }^{(13)}$ suggests that abdominal adipose tissue accumulation was closely associated with cardiovascular risk factors in obese children, and among abdominal adipose tissue compartments, visceral fat thickness was strongly correlated with the elastic properties of the abdominal aorta.

\section{Genetics of visceral fat levels}

The studies of members of the Framingham Heart Study showed that heritability values for VAT was $36 \%{ }^{(7)}$. Twin analyses of BMI and waist circumference in a UK sample of 5092 twin pairs aged 8-11 years showed that $60 \%$ of the heritability of waist circumference was common to BMI, but $40 \%$ was due to different genetic factors ${ }^{(39)}$. The authors claimed that the aetiological significance of visceral fat stores, as compared with other fat stores, may therefore be related to different underlying genetic factors.

Evidence from the Quebec Family Study and the HERITAGE Family Study indicates that between 50 and $55 \%$ of the variance in visceral fat levels, adjusted for total fatness, is attributable to genetic factors ${ }^{(40)}$. Additionally, a major gene hypothesis for visceral fat was supported in both the Quebec Family Study and HERITAGE Family Study. However, after adjustment for total fat mass, the support for a major gene was reduced, suggesting that a major gene which affects fat mass may also affect visceral fat either directly (pleiotropy) or indirectly.

From the Human Obesity Gene Map, introduced by Rankinen et al. ${ }^{(41)}$, it appears that phenotypes reflecting body fat distribution (abdominal visceral and subcutaneous fat, waist:hip ratio, waist circumference, sagittal diameter) were associated with: ACE, ADIPOQ, ADRB2, APOAQ, FABP2, LTA, MTTP, PLIN, PPARG and UCP1 (angiotensin-converting enzyme, adiponectin, $\beta$-2-adrenergic receptor, apoAQ, fatty acid-binding protein 2 , lymphotoxin- $\alpha$, microsomal TAG transfer protein, perilipin, PPAR- $\gamma$ and uncoupling protein 1 genes).

Results of the Quebec Family Study, in which both adults and children participated, showed that the Pro12Ala polymorphism in the gene encoding the transcription factor PPAR, alone or in interaction with dietary fat intake, was associated significantly with waist circumference. Waist circumference was also modulated by an interaction between the ghrelin (GHRL) Leu72Met polymorphism and dietary fat intake, by an interaction between the guanine nucleotide binding protein ( $\mathrm{G}$ protein) $\beta$ polypeptide 3 (GNB3) 825C-T and dietary fat intake, and was also positively associated with dietary fat intake in GNB3 825C/825C homozygotes and 825C/825T heterozygotes $^{(42)}$.

\section{Ethnicity}

Studies among adults showed that white men had greater total VAT volume than African-American men, as well as greater $\mathrm{L}_{4}-\mathrm{L}_{5}$ VAT area and maximum area, whereas African-American and white women did not differ in total VAT volume, $\mathrm{L}_{4}-\mathrm{L}_{5}$ area, or maximum VAT area ${ }^{(6)}$. Compared with Europeans, the Chinese and South Asian participants had a relatively greater amount of abdominal adipose tissue, and this difference was more pronounced with $\mathrm{VAT}^{(43)}$

In Caucasian and African-American obese and non-obese boys and girls, the regression slope between VAT and SAT was significantly lower in African-Americans compared with Caucasians (0.17 (SD 0.02) v. 0.23 (SD 0.02) of VAT per $\mathrm{cm}^{2}$ of SAT $)^{(44)}$. This finding suggests that the rate of accumulation of VAT relative to SAT is $26 \%$ lower in African-American than in Caucasian children. Huang et al. ${ }^{(45)}$ also stated that whites showed a higher visceral fat growth than did African-Americans. The difference was 1.9 (SE 0.8$) \mathrm{cm}^{2} /$ year, but there was no ethnic difference for 
growth of subcutaneous abdominal fat or total body fat. Brambilla et al. ${ }^{(24)}$ found that Hispanics showed significantly higher VAT values than Caucasians (44 (SD 22) v. 38 (SD 22) $\mathrm{cm}^{2}$ ). However, VAT was similar in Caucasians and Hispanics after correction for SAT and for BMI.

He et al. ${ }^{(46)}$, based on two different measures of body fat distribution, DXA and skinfolds, demonstrated that among girls, Asians had lower gynoid fat than whites and AfricanAmericans in all pubertal groups. Among boys, Asians had less gynoid fat measured by DXA in early puberty and late puberty.

Many studies show that Indians have more body fat at each BMI and higher levels of central obesity (measured as waist circumference, waist:hip ratio and visceral fat mass) compared with Caucasians and black Africans ${ }^{(47-49)}$. This thin-fat phenotype is present at birth ${ }^{(50)}$. Indian babies are centrally adipose but thin in muscle and viscera (proteinrich tissues). Thus, it can be concluded from the studies presented that ethnic differences of adipose tissue among children and youth are significant and should be definitely considered in further analyses.

\section{Sex differences}

Adults males have greater amounts of VAT than females, even after taking differences in total body fat into $\operatorname{account}^{(8,51-53)}$. No significant sex differences in IAAT area in prepubertal children were noted by Goran et al. ${ }^{(44)}$, Huang et al. ${ }^{(45)}$ and Saelens et al. ${ }^{(54)}$, but some differences before the onset of puberty have been noted in other studies $^{(46,55,56)}$.

Sex explained only $1.8 \%$ of VAT variance among 7 - to 16-year-old children and the VAT-SAT relationship did not differ between male and female subjects in both prepubertal and pubertal children ${ }^{(24)}$. In the study of Benfield et al. ${ }^{(25)}$, volumes of MRI-derived VAT were 117.2 (SD 114.1) $\mathrm{cm}^{3}$ for boys and 154.2 (SD 111.7) $\mathrm{cm}^{3}$ for girls, but boys had higher VAT:SAT ratios (0.13 (SD 0.06)) than girls (0.10 (SD 0.04)), indicating proportionately more adipose tissue deposited intra-abdominally.

Thus, the studies presented do not give explicit results concerning sex differences and their influence on VAT amount among children and youth both before puberty as well as at the stage of puberty.

\section{Age and level of development}

Goran et al. ${ }^{(44)}$ found that the rate of change in IAAT in African-American prepubertal children (7.6 (SD 1.7) years of age at baseline) over 2 years was $4 \cdot 3(\mathrm{SD} 7 \cdot 3) \mathrm{cm}^{2} /$ year. Further investigations showed that the rate of change in VAT over a 3- to 5-year period in white and African-American children (8.1 (SE 1.6) years of age at baseline) was 5.2 (SE $2 \cdot 2$ ) $\mathrm{cm}^{2} /$ year $^{(45)}$. In 7 - to 16 -year-old subjects, age explained $7.3 \%$ of VAT variance ${ }^{(24)}$. An investigation of changes in the amount of VAT carried out by Fox et al. ${ }^{(18)}$ among the same children aged 11 and 13 years showed that for boys there was a mean percentage increase in waist scan area of $8 \%$. This was accompanied by an increase of $69 \%$ in intra-abdominal fat area but only $19 \%$ increase in subcutaneous fat area. There was no mean increase in non-adipose tissue area so that the $8 \%$ increase in cross-sectional area and $10 \%$ increase in waist circumference were due to additional intra-abdominal fat deposition $\left(12 \cdot 3 \mathrm{~cm}^{2}\right)$ and subcutaneous fat deposition $\left(14.9 \mathrm{~cm}^{2}\right)$. This was accompanied by a significant increase in the IAAT:SAT ratio from 0.31 to 0.39 and an increase in the percentage of total fat that was deposited as visceral fat. For females there was an increase of $17 \%$ in waist crosssectional area. Intra-abdominal fat area increased significantly by $48 \%$. However, there was a $78 \%$ increase in subcutaneous adiposity, with the result that the IAAT:SAT ratio significantly reduced by $10 \%$ from 0.39 to 0.35 .

Interesting results concerning VAT development were also brought to light by investigations of children with low birth weight. Children born small for gestational age tend to develop catch-up growth in infancy and to become overweight. They have higher fasting insulin and insulinlike growth factor-1 levels, and a marked shift from abdominally subcutaneous to visceral fat, and they tend to be viscerally adipose and hypo-adiponectinaemic, even when they are not overweight ${ }^{(57)}$. At the age of 6 years the average amount of VAT was in small-for-gestational-age children more than $50 \%$ higher than in children born appropriate to gestational period ${ }^{(58)}$. The 0 - to 2-year-olds' increment in weight $z$-score together with the 2- to 6-yearolds' increment in fasting insulin accounted for $62 \%$ of VAT variability in 6-year-olds.

Birth weight significantly predicted BMI and total fat mass, but not visceral or subcutaneous fat at age 11 years in overweight Latino adolescents ${ }^{(59)}$. Longitudinally, as participants transitioned into puberty, birth weight did not predict any of the body composition or fat distribution measures.

\section{Puberty status}

Sex differences in body fat distribution exist before the onset of puberty ${ }^{(46,55,56)}$. The results of many investigations suggest that body-composition differences could be mediated by non-hormonal sex-specific factors rather than by sex steroids ${ }^{(46,56,60)}$. Goran et al. ${ }^{(44)}$ showed that the rate of change in IAAT was similar among those children remaining prepubertal $\left(4.6(\mathrm{SD} 2 \cdot 1) \mathrm{cm}^{2} /\right.$ year) compared with those children who entered puberty (5.6 (SD 2.1) $\mathrm{cm}^{2} /$ year). Fat distribution of late pubertal boys was more 'android' than prepubertal boys, but late pubertal girls did not differ consistently from prepubertal girls ${ }^{(46)}$. These findings suggested that the greater sexual dimorphism of fat distribution in late puberty compared with prepuberty may be attributable to larger changes in boys, with smaller changes in girls. Studies of children and adolescents aged 7-16 years have shown that pubertal status explained $12.4 \%$ of VAT variance ${ }^{(24)}$.

Further studies need to ascertain the specific contribution of biological maturation to fat distribution. Literature dealing with abdominal SAT and VAT in children commonly uses stage of pubertal maturation as a maturity indicator $^{(18,36,55)}$. Grouping subjects by stage of pubertal maturation may overlook variation in SAT and VAT associated with chronological age per se, independent 
of stage of sexual maturation. Further, individuals within specific stages of sexual maturation may be in different phases of the adolescent growth spurt ${ }^{(61)}$. At younger ages, subjects are generally described as prepubertal; however, there are often maturity differences among prepubertal children, and the only indicator of maturation available before the overt manifestation of secondary sex characteristics is skeletal age. It is necessary to explain how much of the variation in fatness and the distribution of abdominal SAT and VAT can be attributed to biological maturation independent of chronological age and body size.

\section{Influence of body fat on visceral adipose tissue}

It is clear that a proportion of the variance in VAT is explained by total fat mass, although interpretation of findings is complicated by strong multicollinearity among VAT, SAT and total body fat ${ }^{(44)}$. Fox et al. ${ }^{(7)}$ showed that in obese $v$. control adolescents the majority of excess abdominal adipose tissue was found subcutaneously (353 (SD 94) ข. 79 (SD 61) $\mathrm{cm}^{2}$ ), although there was still greater VAT in the obese children (49 (SD 21) v. $22\left(\operatorname{SD~11)} \mathrm{cm}^{2}\right)$. The correlation between VAT and total body fat in prepubertal children was $0 \cdot 81^{(44)}$. However, the relationship between VAT and total body fat was not significant after adjusting for SAT. The correlation between whole-body fat and SAT was higher $(r$ 0.96) than between whole-body fat and VAT $(r 0.66)$ in 8-year-old children at risk of obesity ${ }^{(54)}$. Huang et al. ${ }^{(45)}$ found that growth of visceral fat remained significant after adjusting for growth of subcutaneous abdominal fat, implying that the acquisition of the two abdominal fat compartments may involve different physiological mechanisms.

In children and adolescents, in whom total adiposity is changing rapidly partly due to increases in body size, it is important to adjust VAT (or SAT) for height.

\section{Hormones and their relationship to fat distribution}

Hormones influencing body fat distribution include growth hormone $(\mathrm{GH})$, sex steroids, cortisol and insulin ${ }^{(62)}$. Sex steroids and GH stimulate lipolysis while cortisol and insulin promote fat deposition. An overly sensitive hypothalamic-pituitary-adrenal (HPA) axis may exist in obesity and disrupt the balance between the lipogenic effect of cortisol and insulin and the lipolytic effect of sex steroids and $\mathrm{GH}^{(63)}$. $\mathrm{GH}$ treatment selectively reduces the abdominal visceral fat of children with $\mathrm{GH}$ deficiency ${ }^{(62,63)}$. Misra et al. (64) found that lower peak $\mathrm{GH}$ on the GH-releasing hormone-arginine stimulation test in overweight girls was associated with visceral obesity. Studies of Roemmich et al. ${ }^{(65)}$ on the relationship between endogenous $\mathrm{GH}$ release and adiposity showed no significant relationship between VAT area and GH secretory characteristics. Further studies also showed that among teenagers total body fat, but not VAT, was related to alterations in GH neuroregulation $^{(66)}$. During adulthood there is an inevitable decrease in sex steroid secretion and increase in VAT resulting in reduced $\mathrm{GH}$ secretion, which may initiate a vicious cycle of further gains in VAT and reductions in GH secretion.
In contrast, pubertal increases in sex steroid secretion are a robust stimulus for $\mathrm{GH}$ secretion and are protective against gains in VAT, which may account for the weak relationship in adolescents, but not in the prepubertal youth who have yet to experience a reawakening of the hypothalamicpituitary axis. Although sex steroid concentrations may explain some of the differences between the role of VAT in modulating GH secretion in youths and adults, the similar relationship among VAT and GH secretion in both prepubertal and pubertal children suggests additional age-related differences.

The relationship between changes in serum sex steroid concentrations and alterations in body fat distribution in children and youth has not been widely studied. Studies among adult males have shown that serum testosterone concentrations are inversely correlated with $\operatorname{VAT}^{(63,67,68)}$. Testosterone may limit abdominal visceral fat accrual by reducing abdominal adipose tissue lipoprotein lipase activity and TAG uptake, while increasing the rate of TAG release from abdominal fat ${ }^{(69)}$. Serum androgen concentrations are directly related to the amount of TAG in VAT in women. However, the amount of visceral fat is thought to be a function of the oestrogen-androgen balance than androgens per $s e^{(63)}$. Oestrogens tend to decrease visceral fat accumulation by down-regulating the androgen receptor. Another mechanism for the effects of oestrogens on the determination of body fat distribution is an indirect one, i.e. on the hypothalamus and increasing GH secretion ${ }^{(14)}$. Cross-sectional data of early pubertal girls show that higher oestrogen concentrations are associated with a gynoid distribution of body fat ${ }^{(70)}$, while long-term studies showed that body fat distribution, rather than body fat mass was related to the total and the non-sex-hormone-binding globulin-bound plasma levels of oestradiol and testosterone at the onset of puberty ${ }^{(71)}$

Garnett et al. ${ }^{(56)}$, investigating relationships between hormones and body composition in prepubertal children, claimed that abdominal fat percentage was correlated with insulin-like growth factor-1, oestradiol and testosterone concentrations. When the sexes were examined separately, the correlation between abdominal fat percentage and oestradiol concentrations was significant only in the boys ( $r$ 0.33), and the correlations between abdominal fat percentage and insulin-like growth factor-1 and testosterone concentrations were not significant in either girls or boys. The only significant predictor of abdominal fat percentage was testosterone, which again explained $4 \%$ of the variation.

Björntorp $^{(63)}$ has suggested that in adults an oversensitive HPA axis may be the primary hormonal attribute leading to an abdominal distribution of fat. Thus the increase in cortisol levels during puberty ${ }^{(72)}$ or an oversensitive HPA axis in an adolescent may influence body fat distribution. Weigensberg et al. ${ }^{(73)}$ confirmed in Latino youth with the metabolic syndrome that morning serum cortisol level was significantly related to directly measured IAAT. Adipose tissue-specific regulation of glucocorticoid metabolism is primarily determined by the enzyme 11ß-hydroxysteroid dehydrogenase type 1 (11ß-HSD1), which catalyses the conversion of cortisone to hormonally active cortisol ${ }^{(74,75)}$. 11 -HSD1 is highly 
expressed in VAT. Andrew et al. ${ }^{(76)}$ demonstrated that VAT contributes substantially to the splanchnic regeneration of cortisol and it is possible that increased $11 \beta$-HSD1 activity in visceral adipose results in increased cortisol delivery to the liver and that change in adipose tissue metabolism of cortisol reaches far beyond adipose tissue itself.

The results of 3 years of observing 8-year-olds showed that an annual increase of approximately $5 \%$ in fasting insulin was associated with $1 \mathrm{~cm}^{2}$ visceral fat gain per year, independent of subcutaneous abdominal fat ${ }^{(77)}$, but the rate of change in visceral fat has no effect on insulin sensitivity. According to Travers et al. ${ }^{(78)}$, puberty is associated with a transient increase in serum insulin concentrations and reduced insulin sensitivity that is related to increased adiposity. Insulin has a potent effect on the increase of lipogenesis, and serum insulin concentrations are directly related to the amount of visceral fat ${ }^{(27)}$. Pubertal girls have a lower insulin sensitivity than pubertal boys ${ }^{(78)}$. These data suggest that the greater insulin sensitivity of boys may cause relatively more fat to be deposited in their visceral depots. Roemmich et al. ${ }^{(79)}$ found that abdominal visceral fat may increase insulin resistance at puberty beyond the resistance due to total body fat. The intra-abdominal fat area in massively obese adolescent girls was associated with increased insulin levels, but there was a strong negative correlation between serum sex hormone-binding globulin level and the area of $\mathrm{VAT}^{(80)}$.

The pubertal changes in serum hormone concentrations are related to the coincident changes in body fat distribution. However, the interactions of the hormonal axes with one another and with the specific fat depots, and changes in these interactions during the transition to puberty, are not yet fully understood. Detailed investigations should be carried out to check the influence of changes in sex hormone levels during the adolescent period on the amount of visceral fat depots. Data from adults may not be directly applicable to youth.

\section{Stress}

Some studies suggest that visceral adiposity could represent a non-optimal physiological adaptation to stress $^{(81,82)}$. The relationship between stress reactivity and central adiposity in children has not been widely studied. Studies of adolescents have shown that blood pressure reactivity to laboratory stress tasks is associated with a greater abdominal girth ${ }^{(83)}$ and waist:hip ratio ${ }^{(84)}$. Stress-induced activation of the HPA axis may contribute to the antecedents of the metabolic syndrome by promoting central adiposity ${ }^{(85-88)}$ and inducing an inflammatory response and insulin resistance ${ }^{(89,90)}$. The associations between central adiposity and metabolic dysregulation occur developmentally earlier than adolescence ${ }^{(85-87)}$, so it is likely that the association between psychological stress reactivity and central adiposity also occurs before adolescence.

Studies of youth that used blood pressure reactivity as a measure of the cardiovascular response to psychological stress found an inverse ${ }^{(91)}$ or no relationship ${ }^{(92-94)}$ between blood pressure reactivity and total adiposity. Roemmich et al. ${ }^{(95)}$, based on heart rate activity, showed that reactivity to psychological stress may initiate the antecedents of CVD before adolescence by increasing total and central adiposity. Future studies should determine whether stress reactivity increases the adiposity of youth by increasing their consumption of energy-dense snack foods and decreasing their willingness to be physically active.

\section{Physical activity and cardiorespiratory fitness}

Physical activity is a critical determinant of adults' visceral fat, even independently of relationships between physical activity and whole-body fat and between whole-body fat and visceral adiposity ${ }^{(96-98)}$. Ohkawara et al. ${ }^{(99)}$ analysed a dose-response relationship between aerobic exercise and visceral fat among adults based on literature published between 1966 and 2006. They stated that at least $10 \mathrm{MET} / \mathrm{h}$ per week (metabolic equivalents/h per week) in aerobic exercise such as walking, light jogging or stationary ergometer usage, is required for visceral fat reduction, and that there is a dose-response relationship between aerobic exercise and visceral fat reduction in obese subjects without metabolic-related disorders.

Studies of the influence of physical exercise on the size of visceral fat tissue among children and teenagers has been conducted more seldom than among adults. Positive effects of strength training on VAT in obese prepubertal girls were claimed by Treuth et al. ${ }^{(100)}$. Gutin \& Owens ${ }^{(101)}$ examining obese children aged 7-11 years showed that 4 months of controlled physical training, without dietary intervention, had a favourable influence on VAT. The shared variance between changes in total body fat mass and VAT were relatively low $\left(r^{2} 0 \cdot 13\right)$ compared with the shared variance between changes in total body fat mass and SAT $\left(r^{2} 0 \cdot 42\right)$, suggesting that to a large extent the VAT changes were independent of the total body changes.

Obese adolescents aged 13-16 years who participated in $2 \mathrm{~d}$ of after-school exercise per week plus a lifestyle education programme over an 8-month period showed more favourable changes in visceral fat than did youths who participated in the lifestyle education programme alone. The favourable effect on visceral adiposity is noteworthy because this fat depot was found to be the most powerful of the adiposity measures for explaining variance in lipidlipoprotein measures in these subjects at baseline ${ }^{(102)}$. They found no evidence that moderate- and high-intensity physical training differed in their effects on body composition.

In a study by Saelens et al. ${ }^{(54)}$, physical activity was an independent correlate of children's visceral fat, with greater physical activity associated with lower fat accumulation in this depot. After controlling for whole-body fat, greater physical activity was only associated with lower VAT, not SAT. Relationships between children's physical activity and both whole-body fat and visceral fat were only evident with the use of a more objective measure of activity than with a self-report measure.

The studies of Barbeau et al. ${ }^{(103)}$ showed that a 10-month after-school physical activity programme among girls aged 8-12 years with correct body mass can lead to beneficial changes in body composition. Compared with the control group, the intervention group had a relative decrease in VAT 
and the improvements in visceral tissue were larger than those in SAT. It was noteworthy that the control and intervention groups differed in changes in VAT, but not waist circumference.

In Irish boys waist circumference was inversely related to fitness $(r-0.503)$ and to vigorous activity $(r-0.31)$, and was positively related to inactivity $(r 0.33)^{(104)}$. In Irish girls waist circumference was related to fitness $(r-0.286)$ but not to specific components of physical activity. Similar associations have also been reported when physical fitness was measured as lower limb explosive strength, abdominal endurance strength, or speed/agility instead of cardiorespiratory fitness ${ }^{(105)}$. Data from the AVENA (Alimentación y Valoración del Estado Nutricional en Adolescentes (Food and Assessment of the Nutritional Status of Spanish Adolescents)) study show that both moderate to high levels of cardiorespiratory fitness are associated with lower abdominal adiposity ${ }^{(106)}$. The same inverse association with cardiorespiratory fitness was observed when VAT was measured using $\mathrm{CT}^{(107)}$ or $\mathrm{MRI}^{(108)}$.

Thus, most of the studies carried out confirm a positive influence of physical activity on the amount of VAT. However, the presented results should be approached cautiously. The meta-analysis of Rowlands et al. (109) suggests that there is a small to moderate relationship between body fat and activity in children and the size of the relationship depends on the activity measure used. The results of this meta-analysis would suggest that direct measures of movement, such as observation or motion counter methods, are the best methods for the assessment of the relationship of activity levels with health.

\section{Nutrition}

According to Bouchard et al. ${ }^{(110)}$, positive energy balance does not appear to be a strong determinant of abdominal visceral fat, as is the case with other body fat phenotypes. $\mathrm{Ku}$ et al. ${ }^{(111)}$ also showed that among children aged $4-10$ years there were no significant correlations between dietary fat and body fat or fat distribution indices after adjusting for non-fat energy intake and total lean tissue mass. There was some suggestion in the study of Saelens et al. ${ }^{(54)}$ that dietary factors were related to the girls' visceral fat accumulation, although not in the regression model that accounted for whole-body fat. Stallmann-Jorgensen et al. ${ }^{(20)}$, examining teenagers aged $14-18$ years, claimed that among many analysed feeding variables energy intake was the sole and the negative predictor of VAT. This dependence suggested that a positive energy balance is mainly the result of a low energy expenditure. Possible, also, is the under-reporting of energy intake by adolescents with greater adiposity. Syme et al. ${ }^{(36)}$ showed that subjects with high and low VAT did not differ in food intake (or physical activity). The authors speculate they may vary in metabolic rate and/or genetic predisposition for body fat distribution. It was also possible that subjects with higher VAT were less active and/or had higher energy intake in the past. Gutin et al. ${ }^{(102)}$, examining obese adolescents, stated that baseline VAT was higher in the youths with a relatively small carbohydrate intake (implying a larger proportion of protein and fat). The above-cited results of the Quebec Family Study showed that each $10 \mathrm{~g}$ increment in fat intake was associated with an increase of $1.2 \mathrm{~cm}$ in waist circumference among Pro12/Pro12 homozygotes ${ }^{(42)}$.

Studies among adults showed that acute energy restriction, using very-low-energy diets, produces early preferential loss of $\mathrm{VAT}^{(112)}$. Results of some studies suggest that in reducing deposits of visceral tissue, the glycaemic index and glycaemic load of consumed products may be very important. VAT cells have a two-fold higher glucose uptake rate compared with SAT cells ${ }^{(113)}$. Glucose raises insulin concentration, which can stimulate $11 \beta$-HSD1, increase active cortisol in visceral fat, and enhance visceral fat accumulation ${ }^{(114)}$. Feeding rats a high-glycaemic index starch diet resulted in higher visceral fat and larger adipocyte volume than did feeding lowglycaemic index starch ad libitum ${ }^{(115-117)}$.

To sum up, it has to be stated that the issue of influence of eating habits on the amount of VAT among children and youth is a very poorly examined one. Studies initiated by Benfield et al. ${ }^{(118)}$ can provide some interesting results.

\section{Smoking and drinking}

Studies of abdominal obesity indicated by anthropometric methods among adults confirm that alcohol consumption $^{(119,120)}$ and smoking ${ }^{(121)}$ are positively associated with central obesity. The influence of behavioural risk factors on VAT deposition in children and adolescents has not been widely studied. In adolescent females smoking and drinking, even at low levels, appear to be associated with increased VAT deposition. Smoking and alcohol use at 4 years after menarche was associated with the change in VAT over the 4-year period before, and after adjustment for total body fat ${ }^{(122)}$.

\section{Conclusions}

VAT quantities, to some extent, seem to be independent of general fatness as far as children and adolescents are concerned. The results of the analysis confirm Goran's ${ }^{(123)}$ observations which suggest that accumulation of VAT in children is influenced by genetic factors, ethnicity, growth and maturation, as well as 'modifiable' factors, such as those associated with lifestyle. The effects of puberty are probably related to influences such as different levels of sex hormones between the sexes.

Similarly to adults, visceral fat deposition in children appears more strongly related to various cardiovascular and diabetes risk factors than does whole-body fat. However, Benfield et al. ${ }^{(25)}$ stated that among children the IAAT represented less than $10 \%$ of total abdominal fat, so that almost $90 \%$ of adiposity is subcutaneous storage. This would suggest that, at this age, the impact of visceral fat deposition on metabolic parameters is likely to be small, but similarly to adults the deposition of VAT is known to increase with age. Early intervention would prevent adults from excessive development of abdominal obesity and its metabolic consequences.

Research carried out so far on factors responsible for deposition of VAT among children and adults was usually 
conducted in small groups in terms of their size. As a result, many times individuals of a different age, body size, maturity status, general fatness, and sometimes even of a different ethnic origin, were compared. Thus, results achieved by particular authors were often inexplicit and difficult to interpret.

An essential research problem is the fact that direct measurements of VAT amount by means of such methods as CT or MRI are expensive and hardly available in the case of epidemiological studies and, what is more, CT is not advisable in the case of repeated measurements among children and youth due to exposure to ionising radiation. Thus, in epidemiological studies, and particularly long-term studies, it is essential to use indirect methods, that is, mainly anthropometric measurements. The strongest relationships with the amount of VAT were noted with reference to waist circumference, sagittal diameter and trunk skinfolds. However, it has to remembered that while using them, we are not able to determine VAT without SAT. Thus, it will be particularly useful to identify the indicator which will help better than others to determine the VAT:SAT ratio. Studies conducted so far have given inexplicit results. In one case it has been found out that sagittal diameter can be this indicator $^{(21)}$, while in others, $\mathrm{BMI}^{(25)}$.

To sum up, it has to be stated that studies carried out in the future concerning different factors influencing deposition of VAT among children and youth should first of all concentrate on:

(1) carrying out long-term analyses among children of different ethnic groups, which should begin in the period of prepuberty and which should cover the whole period of puberty till adulthood. They would let us identify the age at which individual types of adipose tissue could be recognised;

(2) carrying out long-term studies considering physiological changes of hormone metabolism during puberty which would let us determine more precisely the influence of sex hormones on deposition of adipose tissue at this period;

(3) drawing up norms specifying the amount of VAT among healthy children. Especially useful would be the norms covering the measurement of VAT amount carried out among the same children both by means of a direct method as well as indirect ones;

(4) identification of an anthropometric indicator that will help us to determine the VAT:SAT ratio in the most precise way;

(5) broader studies of the influence of eating habits on developing VAT deposit among children and youth. From the review of the literature it turns out that it is an issue which has been analysed very rarely both among adults, as well as children and youth;

(6) determining what intensity and what kind of physical activity will be the most efficient in reduction of VAT, by means of direct measures of activity;

(7) broader examination of the influence of drinking alcohol and smoking cigarettes on distribution of adipose tissue, as most of the data concerning this problem were collected while examining only adults.

\section{Acknowledgements}

The present review was supported by Jan Kochanowski University $(247 / w)$. The research received no specific grant from any funding agency in the public, commercial or notfor-profit sectors.

There are no conflicts of interest.

\section{References}

1. Freedland ES (2004) Role of a critical visceral adipose tissue threshold (CVATT) in metabolic syndrome: implications for controlling dietary carbohydrates: a review. Nutr Metab (epublication 5 November 2004).

2. Shen W, Wang ZM, Punyanita M, et al. (2003) Adipose tissue quantification by imaging methods: a proposed classification. Obes Res 11, 5-16.

3. Wang ZM, Pierson RN \& Heymsfield SB (1992) The five-level model: a new approach to organizing bodycomposition research. Am J Clin Nutr 56, 19-28.

4. Heymsfield SB \& Wang ZM (1997) Human body composition. Advances in models and methods. Ann Rev Nutr 17, 527-558.

5. Snyder WM, Cook MJ, Nasset ES, et al. (1975) Report of the Task Group on Reference Man. Oxford, UK: Pergamon Press, ICRP publication 23.

6. Demerath EW, Sun SS, Rogers N, et al. (2007) Anatomical patterning of visceral adipose tissue: race, sex, and age variation. Obesity 15, 2984-2993.

7. Fox CS, Massaro JM, Hoffmann U, et al. (2007) Abdominal visceral and subcutaneous adipose tissue compartments: association with metabolic risk factors in the Framingham Heart Study. Circulation 116, 39-48.

8. Bray GA, Jablonski KA, Fujimoto WY, et al. (2008) Relation of central adiposity and body mass index to the development of diabetes in the Diabetes Prevention Program. Am J Clin Nutr 87, 1212-1218.

9. Hoffer FA (2005) Magnetic resonance imaging of abdominal masses in the pediatric patient. Semin Ultrasound CT MRI 26, 212-223.

10. Shen W, Punyanita M, Wang ZM, et al. (2004) Visceral adipose tissue: relations between single-slice areas and total volume. Am J Clin Nutr 80, 271-278.

11. Siegel MJ, Hildebolt CF, Bae KT, et al. (2007) Total and intraabdominal fat distribution in preadolescents and adolescents: measurement with MR imaging. Radiology 242, 846-856.

12. Iacobellis G (2005) Imaging of visceral adipose tissue: an emerging diagnostic tool and therapeutic target. Curr Drug Targets Cardiovascular Haematol Disord 5, 345-353.

13. Polat TB, Urganci N, Caliskan KC, et al. (2008) Correlation of abdominal fat accumulation and stiffness of the abdominal aorta in obese children. $J$ Pediatr Endocrinol Metab 21, 1031-1040.

14. Wajchenberg BL (2000) Subcutaneous and visceral adipose tissue: their relation to the metabolic syndrome. Endocr Rev 21, 697-738.

15. Bouchard C (2007) BMI, fat mass, abdominal adiposity and visceral fat: where is the 'beef'? Int J Obes 31, 1552-1553.

16. Goran MI, Gower BA, Treuth M, et al. (1998) Prediction of intra-abdominal and subcutaneous abdominal adipose tissue in healthy pre-pubertal children. Int J Obes Relat Metab Disord 22, 549-558.

17. Benfield LL, Peters DM, Fox KR, et al. (2008) Validity of dual energy X-ray absorptiometry for the estimation of MRI-assessed abdominal adiposity in children. 16th 
European Congress on Obesity, Geneva, Switzerland, 14-17 May 2008 (summary). Int J Obes (Lond) 32, Suppl. 1, S140.

18. Fox KR, Peters DM, Sharpe P, et al. (2000) Assessment of abdominal fat development in young adolescents using magnetic resonance imaging. Int J Obes 24, 1653-1659.

19. Ball GD, Huang TT, Cruz ML, et al. (2006) Predicting abdominal adipose tissue in overweight Latino youth. Int $J$ Pediatr Obes 1, 210-216.

20. Stallmann-Jorgensen IS, Guttin B, Hatfield-Laube JL, et al. (2007) General and visceral adiposity in black and white adolescents and their relation with reported physical activity and diet. Int J Obes 31, 622-629.

21. Asayama K, Dobashi K, Hayashibe H, et al. (2002) Threshold values of visceral fat measures and their anthropometric alternatives for metabolic derangement in Japanese obese boys. Int J Obes 26, 208-213.

22. Asayama K, Hayashibe H, Endo A, et al. (2005) Threshold values of visceral fat and waist girth in Japanese obese children. Pediatr Int 47, 498-504.

23. Owens S, Litaker M, Allison J, et al. (1999) Prediction of visceral fat adipose tissue from simple anthropometric measurements in youths with obesity. Obes Res 7, 16-22.

24. Brambilla P, Bedogni G, Moreno LA, et al. (2006) Crossvalidation of anthropometry against magnetic resonance imaging for the assessment of visceral and subcutaneous adipose tissue in children. Int J Obes 30, 23-30.

25. Benfield LL, Fox KR, Peters DM, et al. (2008) Magnetic resonance imaging of abdominal adiposity in a large cohort of British children. Int J Obes 32, 91-99.

26. Araki S, Dobashi K, Kubo K, et al. (2008) Plasma visfatin concentration as a surrogate marker for visceral fat accumulation in obese children. Obesity (Silver Spring) 16, 384-388.

27. Caprio S, Hyman L, McCarthy S, et al. (1996) Fat distribution and cardiovascular risk factors in obese adolescent girls: importance of the intraabdominal fat depot. Am J Clin Nutr 64, 12-17.

28. Caprio S (1999) Relationship between abdominal visceral fat and metabolic risk factors in obese adolescents. Am J Hum Biol 11, 259-266.

29. Brambilla P, Manzoni P, Agostini G, et al. (1999) Persisting obesity starting before puberty is associated with stable intraabdominal fat during adolescence. Int $\mathrm{J}$ Obes Relat Metab Disord 23, 299-303.

30. Mamalakis G, Kafatos A, Manios Y, et al. (2002) Abdominal vs buttock adipose fat: relationship with children's serum lipid levels. Eur J Clin Nutr 56, $1081-1086$.

31. Daniels SR, Morrison JA, Sprecher DL, et al. (1999) Association of body fat distribution and cardiovascular risk factors in children and adolescents. Circulation 99, $541-545$

32. He Q, Horlick M, Fedun B, et al. (2002) Trunk fat and blood pressure in children through puberty. Circulation 105, $1093-1098$

33. Kortelainen ML \& Särkioja T (2001) Visceral fat and coronary pathology in male adolescents. Int $J$ Obes Relat Metab Disord 25, 228-232.

34. Neri D, Espinoza A, Bravo A, et al. (2007) Visceral adiposity and its association with serum lipids in female obese teenagers (article in Spanish). Rev Med Chil 135, 294-300.

35. Druet C, Baltakse V, Chevenne D, et al. (2008) Independent effect of visceral adipose tissue on metabolic syndrome in obese adolescents. Horm Res 70, 22-28.
36. Syme C, Abrahamowicz M, Leonard GT, et al. (2008) Intra-abdominal adiposity and individual components of the metabolic syndrome in adolescence: sex differences and underlying mechanisms. Arch Pediatr Adolesc Med 162, 453-461.

37. Kim JA \& Park HS (2008) Association of abdominal fat distribution and cardiometabolic risk factors among obese Korean adolescents. Diabetes Metab 34, 126-130.

38. Kim JA \& Park HS (2008) White blood cell count and abdominal fat distribution in female obese adolescents. Metabolism 57, 1375-1379.

39. Wardle J, Carnell S, Haworth CMA, et al. (2008) Evidence for a strong genetic influence on childhood adiposity despite the force of the obesogenic environment. Am J Clin Nutr 87, 398-404.

40. Katzmarzyk PT, Pérusse L \& Bouchard C (1999) Genetics of abdominal visceral fat levels. Am J Hum Biol 11, 225-235.

41. Rankinen T, Zuberi A, Chagnon YC, et al. (2006) The human obesity gene map: the 2005 update. Obesity 14, 529-644.

42. Robitaille J, Pérusse L, Bouchard C, et al. (2007) Genes, fat intake, and cardiovascular disease risk factors in the Quebec Family Study. Obesity 15, 2236-2347.

43. Lear SA, Humphries KH, Kohli S, et al. (2007) Visceral adipose tissue accumulation differs according to ethnic background: results of the Multicultural Community Health Assessment Trial (M-CHAT). Am J Clin Nutr 86, 535-539.

44. Goran MI, Nagy TR, Treuth MS, et al. (1997) Visceral fat in Caucasian and African American prepubertal children. Am J Clin Nutr 65, 1703-1708.

45. Huang TT, Johnson MS, Figueroa-Colon R, et al. (2001) Growth of visceral fat, subcutaneous abdominal fat, and total body fat in children. Obes Res 9, 283-289.

46. He Q, Horlick M, Thornton J, et al. (2004) Sex-specific fat distribution is not linear across pubertal groups in a multiethnic study. Obes Res 12, 725-733.

47. Banerji MA, Faridi N, Atluri R, et al. (1999) Body composition, visceral fat, leptin, and insulin resistance in Asian Indian men. J Clin Endocrinol Metab 84, 137-144.

48. Yajnik CS (2001) The insulin resistance epidemic in India: fetal origins, later lifestyle, or both? Nutr Rev 59, 1-9.

49. Yajnik CS (2004) Early life origins of insulin resistance and type 2 diabetes in India and other Asian countries. J Nutr 134, 205-210.

50. Yajnik CS, Lubree HG, Rege SS, et al. (2002) Adiposity and hyperinsulinemia in Indians are present at birth. $J$ Clin Endocrinol Metab 87, 5575-5580.

51. Lemieux S, Prud'homme D, Bouchard C, et al. (1993) Sex differences in the relation of visceral adipose tissue accumulation to total body fatness. Am J Clin Nutr 58, 463-467.

52. Kuk JL, Lee SJ, Heymsfield SB, et al. (2005) Waist circumference and abdominal adipose tissue distribution: influence of age and sex. Am J Clin Nutr 83, 1330-1334.

53. Demerath EW, Shen W, Lee M, et al. (2007) Approximation of total visceral adipose tissue with a single magnetic resonance image. Am J Clin Nutr 85, 362-368.

54. Saelens BE, Seely RJ, van Schaick K, et al. (2007) Visceral abdominal fat is correlated with whole-body fat and physical activity among 8 -y-old children at risk of obesity. Am J Clin Nutr 85, 46-53.

55. Herd SL, Gower BA, Dashti N, et al. (2001) Body fat, fat distribution and serum lipids, lipoproteins and apolipoproteins in African-American and CaucasianAmerican prepubertal children. Int $J$ Obes Relat Metab Disord 25, 198-204. 
56. Garnett SP, Högler W, Blades B, et al. (2004) Relation between hormones and body composition, including bone, in prepubertal children. Am J Clin Nutr 80, 966-972.

57. Ibáñez L, Lopez-Bermejo A, Suárez L, et al. (2008) Visceral adiposity without overweight in children born small-for-gestational-age. J Clin Endocrinol Metab 93, 2079-2083.

58. Ibáñez L, Lopez-Bermejo A, Suárez L, et al. (2008) Early development of visceral fat excess after spontaneous catch-up growth in children with low birth weight. J Clin Endocrinol Metab 93, 925-928.

59. Kelly LA, Lane CJ, Ball GD, et al. (2008) Birth weight and body composition in overweight Latino youth: a longitudinal analysis. Obesity (Silver Spring) 16, 2524-2528.

60. He Q, Horlick M, Thornton J, et al. (2002) Sex and race differences in fat distribution among Asian, AfricanAmerican and Caucasian prepubertal children. J Clin Endocrinol Metab 87, 2164-2170.

61. Malina RM, Koziel S \& Bielicki T (1999) Variation in subcutaneous adipose tissue distribution associated with age, sex, and maturation. Ann Hum Biol 11, 189-200.

62. Roemmich JN \& Rogol AD (1999) Hormonal changes during puberty and their relationship to fat distribution. Am J Hum Biol 11, 209-224.

63. Björntorp P (1996) The regulation of adipose tissue distribution in humans. Int J Obes 20, 291-302.

64. Misra M, Bredella MA, Tsai P, et al. (2008) Low growth hormone and higher cortisol are associated with greater visceral adiposity, intramyocellular lipids, and insulin resistance in overweight girls. Am J Physiol Endocrinol Metab 295, 385-392.

65. Roemmich JN, Clarc PA, Mai V, et al. (1998) Alterations in growth and body composition during puberty. III. Influence of maturation, gender, body composition, fat distribution, aerobic fitness, and energy expenditure on nocturnal growth hormone release during puberty. J Clin Endocrinol Metab 83, 1440-1447.

66. Roemmich JN, Clarc PA, Weltman A, et al. (2005) Pubertal alterations in growth and body composition: IX. Altered spontaneous secretion and metabolic clearance of growth hormone in overweight youth. Med Clin Experim 54, $1374-1383$.

67. Nielsen TL, Hagen C, Wraae K, et al. (2007) Visceral and subcutaneous adipose tissue assessed by magnetic resonance imaging in relation to circulating androgens, sex hormone-binding globulin, and luteinizing hormone in young men. J Clin Endocrinol Metab 92, 2696-2705.

68. Allan CA, Strauss BJ, Burger HG, et al. (2008) Testosterone therapy prevents gain in visceral adipose tissue and loss of skeletal muscle in nonobese aging men. J Clin Endocrinol Metab 93, 139-146.

69. Marin P, Oden B \& Björntorp P (1995) Assimilation and mobilization of triglycerides in subcutaneous abdominal and femoral adipose tissue in vivo in men: effects of androgens. J Clin Endocrinol Metab 80, 1018-1022.

70. De Ridder CM, Bruning PF, Zonderland ML, et al. (1990) Body fat mass, body fat distribution, and plasma hormones in early puberty in females. J Clin Endocrinol Metab 70, $888-893$.

71. De Ridder CM, de Boer RW, Seidel JC, et al. (1992) Body fat distribution in pubertal girls quantified by magnetic resonance imaging. Int $J$ Obes 16, 443-449.

72. Kiess W, Meidert A, Dressendorfer RA, et al. (1995) Salivary cortisol levels throughout childhood and adolescence: relation with age, pubertal stage and weight. Pediatr Res 37, 502-506.
73. Weigensberg MJ, Toledo-Corral CM \& Goran MI (2008) Association between the metabolic syndrome and serum cortisol in overweight Latino youth. J Clin Endocrinol Metab 93, 1372-1378.

74. Seckl JR \& Walker BR (2001) Minireview: 11ßhydroxysteroid dehydrogenase type 1 - a tissue specific amplifier of glucocorticoid action. Endocrinology 142, 1371-1376.

75. Stulnig TM \& Waldhausl W (2004) 11ß-Hydroxysteroid dehydrogenase type 1 in obesity and type 2 diabetes. Diabetologia 47, 1-11

76. Andrew R, Westerbacka J, Wahren J, et al. (2005) The contribution of visceral adipose tissue to splanchnic cortisol production in healthy humans. Diabetes 54, 1364-1370.

77. Huang TT, Johnson MS, Gower BA, et al. (2002) Effect of changes in fat distribution on the rates of change of insulin response in children. Obes Res 10, 978-984.

78. Travers SH, Jeffers BW, Bloch CA, et al. (1995) Gender and Tanner stage differences in body composition and insulin sensitivity in early pubertal children. J Clin Endocrinol Metab 80, 172-178.

79. Roemmich JN, Clars PA, Lusk M, et al. (2002) Pubertal alterations in growth and body composition. VI. Pubertal insulin resistance: relation to adiposity, body fat distribution and hormone release. Int J Obes Relat Metab Disord 26, 701-709.

80. De Simone M, Verrotti A, Iughetti L, et al. (2001) Increased visceral adipose tissue is associated with increased circulating insulin and decreased sex hormone binding globulin levels in massively obese adolescent girls. $J$ Endocrinol Invest 24, 438-444.

81. Drapeau V, Therrien F, Richard D, et al. (2003) Is visceral obesity a physiological adaptation to stress? Panminerva Med 45, 189-195.

82. Kyrou I, Chrousos GP \& Tsigos C (2006) Stress, visceral obesity, and metabolic complications. Ann N Y Acad Sci 1083, 77-110.

83. Goldbacher EM, Matthews KA \& Salomon K (2005) Central adiposity is associated with cardiovascular reactivity to stress in adolescents. Health Psychol 24, 375-384.

84. Barnes VA, Treiber FA, Davis H, et al. (1998) Central adiposity and hemodynamic functioning at rest and during stress in adolescents. Int $J$ Obes Relat Metab Disord 22, 1079-1083.

85. Gower BA, Nagy TR \& Goran MI (1999) Visceral fat, insulin sensitivity, and lipids in prepubertal children. Diabetes 48, 1515-1521.

86. Goran MI, Bergman RN \& Gower BA (2001) Influence of total vs. visceral fat on insulin action and secretion in African American and white children. Obes Res 9, 423-431.

87. Nishina M, Kikuchi T, Yamazaki H, et al. (2003) Relationship among systolic blood pressure, serum insulin and leptin, and visceral fat accumulation in obese children. Hypertens Res 26, 281-288.

88. Rosmond R (2003) Stress induced disturbances of the HPA axis: a pathway to type 2 diabetes? Med Sci Monit $\mathbf{9}$, 35-39.

89. Rosmond R (2005) Role of stress in the pathogenesis of the metabolic syndrome. Psychoneuroendocrinology 30, 1-10.

90. Black PH (2003) The inflammatory response is an integral part of the stress response: implications for atherosclerosis, insulin resistance, type II diabetes and metabolic syndrome X. Brain Behav Immun 17, 350-364.

91. Wilson ME, Harshfield GA, Ortiz L, et al. (2004) Relationship of body composition to stress-induced 
pressure natriuresis in youth. Am $J$ Hypertens 17, $1023-1028$.

92. Barbeau P, Litaker MS \& Harshfield GA (2003) Impaired pressure natriuresis in obese youths. Obes Res 11, 745-751.

93. Pflieger KL, Treiber FA, Davis H, et al. (1994) The effect of adiposity on children's left ventricular mass and geometry and haemodynamic responses to stress. Int J Obes Relat Metab Disord 18, 117-122.

94. Aldo Ferrara L, Soro S, Mainenti G, et al. (1989) Body weight and cardiovascular response to sympathetic stimulation in childhood. Int J Obes 13, 271-277.

95. Roemmich JN, Smith JR, Epstein LH, et al. (2007) Stress reactivity and adiposity of youth. Obesity (Silver Spring) 15, 2303-2310.

96. Kaneley JA, Sames C, Swisher L, et al. (2001) Abdominal fat distribution in pre- and postmenopausal women: the impact of physical activity, age, and menopausal status. Metabolism 50, 976-982.

97. Riechman SE, Schoen RE, Weissfeld JL, et al. (2002) Association of physical activity and visceral adipose tissue in older women and men. Obes Res 10, 1065-1073.

98. Wong SL, Katzmarzyk PT, Nichaman MZ, et al. (2004) Cardiorespiratory fitness is associated with lower abdominal fat independent of body mass index. Med Sci Sports Exerc 36, 286-291.

99. Ohkawara K, Tanaka S, Miyachi M, et al. (2007) A doseresponse relation between aerobic exercise and visceral fat reduction: systematic review of clinical trials. Int J Obes $\mathbf{3 1}$, 1786-1797.

100. Treuth M, Hunter G, Figueroa-Colon R, et al. (1998) Effects of strength training on intra-abdominal adipose tissue in obese prepubertal girls. Med Sci Sports Exerc 30, $1738-1743$

101. Gutin B \& Owens S (1999) Role of exercise intervention in improving body fat distribution and risk profile in children. Am J Hum Biol 11, 237-247.

102. Gutin B, Barbeau P, Owens S, et al. (2002) Effect of exercise intensity on cardiovascular fitness, total body composition, and visceral adiposity of obese adolescents. Am J Clin Nutr 75, 818-826.

103. Barbeau P, Johnson MH, Howe CA, et al. (2007) Ten months of exercise improves general and visceral adiposity, bone, and fitness in black girls. Obesity 15, 2077-2085.

104. Hussey J, Bell C, Bennett K, et al. (2007) Relationship between the intensity of physical activity, inactivity, cardiorespiratory fitness and body composition in 7-10year-old Dublin children. Br J Sport Med 41, 311-316.

105. Brunet M, Chaput JP \& Tremblay A (2006) The association between low physical fitness and high body mass index or waist circumference is increasing with age in children: the 'Quebec en Forme' Project. Int J Obes (Lond) 31, 637-645.

106. Ortega FB, Ruiz JR, Castillo MJ, et al. (2008) Physical fitness in childhood and adolescence: a powerful marker of health. Int J Obes (Lond) 32, 1-11.

107. Lee SJ \& Arslanian SA (2007) Cardiorespiratory fitness and abdominal obesity in youth. Eur J Clin Nutr 61, 561-565.

108. Winsley RJ, Armstrong N, Middelbrooke AR, et al. (2006) Aerobic fitness and visceral adipose tissue in children. Acta Paediatr 95, 1435-1438.
109. Rowlands AV, Ingledew DK \& Eston RG (2000) The effect of type of physical activity measure on the relationship between body fatness and habitual physical activity in children: a meta-analysis. Ann Hum Biol 27, 479-497.

110. Bouchard C, Després J-P \& Mauriège P (1993) Genetic and nongenetic determinants of regional fat distribution. Endocr Rev 14, 72-93.

111. Ku CY, Gower BA, Nagy TR, et al. (1998) Relationship between dietary fat, body fat, and serum lipid profile in prepubertal children. Obes Res 6, 400-407.

112. Chaston TB \& Dixon JB (2008) Factors associated with percent change in visceral versus subcutaneous abdominal fat during weight loss: findings from a systematic review. Int J Obes 32, 619-628.

113. Lundgren M, Buren J, Myrnas T, et al. (2004) Glucocorticoids down-regulate glucose uptake capacity and insulinsignaling proteins in omental but not subcutaneous human adipocytes. J Clin Endocrinol Metab 89, 2989-2997.

114. Bujalska IJ, Kumar S \& Stewart PM (1997) Does central obesity reflect 'Cushing's disease of the omentum'? Lancet 349, 1210-1213.

115. Lerer-Metzger M, Rizkalla SW, Luo J, et al. (1996) Effects of long-term low-glycaemic index starchy food on plasma glucose and lipid concentrations and adipose tissue cellularity in normal and diabetic rats. $\mathrm{Br} J$ Nutr 75, $723-732$.

116. Kabir M, Rizkalla SW, Quignard-Boulange A, et al. (1998) A high glycemic index starch diet affects lipid storagerelated enzymes in normal and to a lesser extent in diabetic rats. $J$ Nutr 128, 1878-1883.

117. Kim JY, Noke LA, Hansen PA, et al. (1999) Insulin resistance of muscle glucose transport in male and female rats fed a high-sucrose diet. Am J Physiol 276, 665-672.

118. Benfield LL, Peters DM, Fox KR, et al. (2009) Relationships between magnetic resonance imaging (MRI) determined abdominal adiposity, physical activity, dietary variables in a cohort of 11-13 year olds. 8th International Symposium on In Vivo Body Composition Studies, New York, USA, 9-12 July 2008 (In the Press).

119. Laitinen J, Pietiläinen K, Wadsworth M, et al. (2004) Predictors of abdominal obesity among 31-y-old men and women born in Northern Finland in 1966. Eur J Clin Nutr 58, 180-190.

120. Schröder H, Morales-Molina JA, Bermejo S, et al. (2007) Relationship of abdominal obesity with alcohol consumption at population scale. Eur J Nutr 46, 369-376.

121. Canoy D, Wareham N, Luben R, et al. (2005) Cigarette smoking and fat distribution in 21828 British men and women: a population-based study. Obes Res 13, $1466-1475$.

122. Must A, Bandini LG, Tybor DJ, et al. (2008) Behavioral risk factors in relation to visceral adipose tissue deposition in adolescent females. Int J Pediatr Obes 3, Suppl. 1, 28-36.

123. Goran MI (1999) Visceral fat in prepubertal children: influence of obesity, anthropometry, ethnicity, gender, diet, and growth. Am J Hum Biol 11, 201-207. 